\title{
Behavioural correlates of an experimental hippocampal epileptiform syndrome in rats
}

\author{
J MELLANBY, P STRAWBRIDGE, GI COLLINGRIDGE, G GEORGE, G RANDS, \\ C STROUD, P THOMPSON
}

From the Department of Experimental Psychology, University of Oxford, UK

SUMMARY Experiments are reported describing assessment of abnormal behaviour of rats in which a chronic epileptiform syndrome has been induced by the injection of tetanus toxin bilaterally into their hippocampi. The abnormal behaviour included hyper-reactivity to a novel environment, intermittent aggression on handling, and abnormally passive response to a strange rat introduced into their home cage. In animals with unilateral injection of toxin, electrical records from the hippocampi have been obtained. They illustrated bilaterally simultaneous discharges and also some independence between the two hippocampi. The discharges were accompanied by overt signs of complex partial seizures during the first few weeks of the syndrome but later occurred without motor signs. In this later stage the rats were somewhat resistant to the convulsant effects of pentylenetetrazol.

Some patients with temporal lobe epilepsy have been reported to show abnormal personality and behaviour. ${ }^{1-3}$ There is controversy among clinicians both concerning the incidence of abnormalities and concerning whether if they do occur they constitute an integral part of the epilepsy or result from adverse social conditions in which epileptics find themselves. One way of investigating this problem is to see whether abnormal general behaviour occurs in animals with experimental epilepsy. We have previously described a chronic, but eventually reversible, epileptiform syndrome in the rat, produced by injecting minute doses of tetanus toxin (bilaterally) into the hippocampus. ${ }^{4}$ This syndrome was apparently produced by a specific pharmacological action ${ }^{5-10}$ of the toxin, since control rats injected similarly with neutralised toxin did not become abnormal, and since there were no gross histological changes in the hippocampus. ${ }^{4}$

The toxin-injected animals not only have intermittent myoclonic-type seizures and automatisms for some weeks but also become extremely reactive to handling by the experimenter and show sporadic spontaneous aggressive behaviour. Furthermore, the

Address for reprint requests : Dr Jane Mellanby, Department of Experimental Psychology, University of Oxford, South Parks Road, Oxford OX1 3UD, UK.

Received 7 February 1981 and in revised form 20 July 1981 Accepted 6 August 1981 rats showed long-term deficits in their ability to learn and to remember, even at times when the animals no longer had fits and electrical activity in their hippocampi would have returned to normal. 1112 The present paper describes the analysis of the behavioural changes seen in the epileptic rats during the epileptiform syndrome. In particular we have assessed quantitatively the hyper-reactivity, the changes in social behaviour, and seizure threshold to pentylenetetrazol. In separate experiments, we have made bilateral electrical recordings from the ventral hippocampi of rats which had been injected unilaterally with tetanus toxin into the ventral hippocampus. (The timing of the initiation and termination of the epileptiform syndrome is similar whether a particular amount of toxin has been injected as a single dose unilaterally or as a divided dose bilaterally (A-K Brink and C Hawkins, unpublished).) The recordings show the time-course of the establishment of the epileptic focus and the characteristics of the hippocampal discharges. The results demonstrate the occurrence of abnormal behaviours in rats with hippocampal epilepsy during the period when the frequency of hippocampal discharges would have been high.

\section{Materials and methods}

Tetanus toxin A tetanus toxin preparation containing $6 \times 10^{6}$ mouse $\mathrm{LD}_{50} / \mathrm{mg}$ was kindly provided by $\mathrm{Dr}$ 
RO Thomson of the Wellcome Research Laboratories. It was dissolved in $0.05 \mathrm{M}$ sodium phosphate buffer ( $\mathrm{pH} 7 \cdot 0$ ) containing $0.2 \%$ gelatine $\mathrm{w} / \mathrm{v}$. Dilutions were made in this mixture. The toxicity of the solutions was assayed $^{13}$ on each day that injections were made into the brains of rats.

Tetanus antitoxin containing 1800 units/ml was also obtained from Dr RO Thomson. Control animals received the same amounts of the same dilutions of toxin as the experimental animals, but mixed with a just-neutralising dose of antitoxin.

Animals Male Sprague-Dawley rats weighing between 250 and $450 \mathrm{~g}$ were used (except in one experiment, where Wistar rats were used).

Operative procedure The rats were anaesthetised with a solution of chloral hydrate BP $(7 \% \mathrm{w} / \mathrm{v}$ dissolved in physiological saline), $2 \cdot 1 \mathrm{ml} / \mathrm{kg}$ body weight, and a solution of sodium pentobarbitone $(6 \% \mathrm{w} / \mathrm{v}$ Nembutal, Abbott), $0.4 \mathrm{ml} / \mathrm{kg}$ body weight. The drugs were given separately by intraperitoneal injection. The rats were then placed in a Kopf stereotaxic instrument. Injections $(2 \times 0.5 \mu$ l bilaterally or $1 \mu$ l unilaterally) were made from a $10 \mu \mathrm{l}$ Hamilton syringe mounted in the instrument's microinjection unit. The injection took place over a period of one minute and the needle was then left in place for a further $3 \mathrm{~min}$ before withdrawal. Injections into the ventral hippocampus were made according to De Groot's Atlas of Rat Neuroanatomy, with co-ordinates anterior $+3.0 \mathrm{~mm}$, lateral $\pm 4.8 \mathrm{~mm}$, and vertical $-2.0 \mathrm{~mm}$.

Implantation of recording electrodes Bipolar electrodes were made of double twisted diamel-coated stainless steel, 0.006 inches $(0.015 \mathrm{~cm})$ diameter. The tips of the two electrodes were separated from each other by $1 \mathrm{~mm}$. Tetanus toxin was injected at the same operation as that in which the electrodes were implanted. The toxin was injected first and the electrode to be implanted on that side was placed stereotaxically $0.5 \mathrm{~mm}$ dorsal to the site of toxin-injection. Another bipolar electrode was implanted in the corresponding position in the opposite, non-injected, hippocampus. The electrodes, plus an earth wire, were wired into a plug which was fixed to the skull of the rat with dental cement.

Recording of hippocampal electrical activity The plugs on the rat's head were connected to a Beckman "Accutrace" 8 channel EEG recorder. At any one time, records from each hippocampus of four rats could be obtained.

Testing of general behaviour of animals The animals were weighed on a Mettler top-loading balance once a week. Their general hyper-reactive behaviour in response to this handling, which involved catching the animals by the tail and putting them on the balance, was assessed on an arbitrary 0-4 scale. 0 meant normal and 4 meant that the rats leapt out of the cage when it was opened and dashed across the room and were only caught with extreme difficulty. Activity in the "home cage" was measured by placing the plastic cage (with minimal disturbance to the occupant) on an Animex activity meter for a period of 10 minutes.

The "open field" was a circular piece of plywood (of diameter $100 \mathrm{~cm})$ with a Perspex side $(30 \mathrm{~cm}$ high). Lines were drawn on the plywood such that it was divided into eight segments, and two concentric (inner and outer) circles were drawn $20 \mathrm{~cm}$ and $60 \mathrm{~cm}$ from the centre. Testing was carried out in a brightly lit room and during the test a loud electric bell was rung at 15 second intervals. The animal was placed in the field and the number of times that it crossed the radial lines and the inner and outer circle in 2 minutes was recorded. In addition, at the end of the testing period the number of faecal boli produced was counted.

The Home Cage Intruder Test The test is similar to that devised by File et al (1979). ${ }^{14}$ The rats, which were housed singly in wire cages, were tested in their own cages and the tests were carried out in the room in which the rats were housed. The responses of the test rat to an unfamiliar rat introduced into the home environment was measured by recording its behaviour toward a normal intruder rat. The behaviour in which the test rat was involved was noted at intervals of 5-10 s. Male SpragueDawley rats of the same batch (and therefore the same size) as the test rats were used as intruder rats. Twelve were used altogether, each being used against one member of each of the two groups of test rats (that is, toxininjected and controls). None of these rats had been used for any previous experimentation and they had not been in contact with the test rats for at least four weeks. The tests were carried out in the third week after operation. The test started on the introduction of the intruder rat into the cage and lasted ten minutes. Intruder rats were marked with dye so that they could easily be distinguished. The behaviours of the test rat were recorded by speaking them into a tape recorder; by this method the rats could be continuously observed. Behaviour was scored as follows: Aggressive actions: nip, box, wrestle, kick, leap on, push, follow, climb on. Passive actions (that is, a passive response to the intruder rat): passive lying on back (this is a gesture of submission elicited by aggressive behaviour of the intruder), run away, climb under, freeze. Other "non-interactive" actions: groom, explore, eat, drink.

Pentylenetetrazol convulsion-time The animals were injected ip with $75 \mathrm{mg} / \mathrm{kg}$ of pentylenetetrazol dissolved in saline and observed for the next 3 minutes. The times until the first visible muscle twitch and the start of a full convulsion were measured. In addition, the general nature of the convulsions were observed. In one experiment the pentylenetetrazol convulsion time was examined 18 days after bilateral intrahippocampal injections of tetanus toxin (or neutralised toxin) (with Sprague-Dawley rats). This was at a time when the toxin-injected animals were having fits and were difficult to handle. In a separate experiment (in which Wistar rats had been used), the pentylenetetrazol convulsion time was measured 5 months after the animals had received bilateral intrahippocampal injections of tetanus toxin 
(or neutralised toxin). At this time, the toxin-injected animals had ceased to have overt fits and their general behaviour had returned to normal.

\section{Results}

\section{ACTIVITY MEASUREMENTS}

The most obvious effect of the injection of small amounts (5-10 mouse LD $_{50}$ ) of tetanus toxin into the hippocampus in the rats, either bilaterally or unilaterally, was that between one and two days later the animals became difficult to handle. When the lid of the cage was removed they would jump out and dash across the room. They appeared very tense when held and would occasionally bite. This hyperreactivity reached a peak at about two weeks after the injection of the toxin and after that the animals became calmer over the next three weeks. This period of maximum reactivity roughly coincided with the period during which overt fits occurred most frequently (see table 1). In order to assess whether this behaviour constituted general hyperreactivity or was an increase in reactivity to stimulation, two experiments were carried out (on the same rats). Two groups of 24 rats were operated upon.

Table 1 General hyperreactivity of rats injected with tetanus toxin into the hippocampus

\begin{tabular}{lll}
\hline $\begin{array}{l}\text { Weeks after } \\
\text { operation }\end{array}$ & Toxin-injected & Controls (neutralised toxin) \\
\hline 1 & $1.93 \pm 0.96$ & $0.30 \pm 0.13$ \\
2 & $2.46 \pm 0.82$ & $0.03 \pm 0.13$ \\
3 & $1.39 \pm 0.90$ & $0.13 \pm 0.23$ \\
4 & $1.46 \pm 0.66$ & $0.07 \pm 0.17$ \\
5 & $0.25 \pm 0.33$ & $0.07 \pm 0.17$ \\
6 & $0.25 \pm 0.26$ & $0.10 \pm 0.28$ \\
9 & $0.57 \pm 1.02$ & $1.13 \pm 0.92$ \\
\hline
\end{tabular}

Rats were injected with either 6-12 $\mathrm{LD}_{50}$ of tetanus toxin or neutralised toxin bilaterally into their ventral hippocampi (12 rats in each group). (The animals were assigned scores from 0 (normal) to 4 on the basis of their behaviour when they were weighed.)

Half were injected bilaterally with tetanus toxin into their ventral hippocampi and half with neutralised toxin. Twenty days after the operation, the animals, which were already housed separately, were transferred to plastic cages suitable for measuring activity on the Animex Activity meter. The following day (that is, when they had had 24 hours in which to become accustomed to their new cages) their activity was assessed over a ten-minute period on the Animex meter. This was done between 8 am and 12 noon-a time when the animals would usually be asleep. Great care was taken not to disturb the animals when the cages were transferred to the mieter. A second measurement of activity was made 12 hours later, between $8 \mathrm{pm}$ and midnight, during the hours of darkness when the animals would normally be awake. Table 2 shows that there were no differences between the groups in the activity in the "home cage" at either time of day. This contrasts markedly with the differences in the response of the experimental and control animals to handling at this time after operation. Quantitative assessment of such hyper-reactivity was attempted on these rats by testing their activity in the open field situation (see Methods). Since the animals are most awake at night, the test was done in the evening (between $8 \mathrm{pm}$ and midnight). Table 3 shows that the toxininjected rats were significantly more active in this situation and this is particularly obvious in the score for crossing the outer circle. By 3 months after injection there was no difference in the behaviour in the open field of the two groups of rats (table 4).

Table 2 Effect of tetanus toxin injected bilaterally into the hippocampus (total 6-12 L $D_{50}$ ) on activity in the home cage 20 days after operation

\begin{tabular}{lcll}
\hline Group & $n$ & Activity & \\
\cline { 3 - 4 } & & Day-time & Night-time \\
\hline $\begin{array}{l}\text { Toxin-injected } \\
\begin{array}{l}\text { Controls } \\
\text { (neutralised toxin) }\end{array}\end{array}$ & 11 & $273( \pm 189)$ & $373( \pm 257)$ \\
$\begin{array}{l}\text { Controls } \\
\text { (unoperated) }\end{array}$ & 6 & $260( \pm 98)$ & $427( \pm 192)$ \\
& & &
\end{tabular}

(The activity was measured using an Animex activity meter. The values are given \pm SD.)

Table 3 The effect of tetanus toxin injected bilaterally into the hippocampus (total 6-12 L $D_{50}$ ) on activity in the "open field" at night 18-25 days after operation

\begin{tabular}{|c|c|c|c|c|c|}
\hline \multirow[t]{2}{*}{ Group } & \multirow[t]{2}{*}{$n$} & \multirow[t]{2}{*}{ Lines crossed } & \multicolumn{3}{|c|}{ Activity measures $/ 2 \mathrm{~min}$} \\
\hline & & & Outer circle crossed & Inner circle crossed & Faecal boli \\
\hline $\begin{array}{l}\text { Toxin-injected } \\
\text { Controls (neutralised toxin) }\end{array}$ & $\begin{array}{l}22 \\
24\end{array}$ & $\begin{array}{l}35.9 \pm 16.6 \\
25.0 \pm 10.5 \\
p<0.025\end{array}$ & $\begin{array}{l}4.9 \pm 3.8^{*} \\
1.7 \pm 1.8 \\
p<0.001\end{array}$ & $\begin{array}{l}1.14 \pm 2.01 \\
0.08 \pm 0.28 \\
\mathrm{p}=0.01\end{array}$ & $\begin{array}{l}2 \cdot 01 \pm 1 \cdot 2 \\
2 \cdot 2 \pm 1 \cdot 1 \\
\mathrm{NS}\end{array}$ \\
\hline
\end{tabular}

The values are given \pm standard deviation. *One rat excluded because too fast to assess. 
Table 4 Effect of tetanus toxin on "open field" activity at night -3 months after operation

\begin{tabular}{|c|c|c|c|c|}
\hline \multirow[t]{2}{*}{ Group } & \multirow[t]{2}{*}{$n$} & \multicolumn{3}{|c|}{ Activity measures $/ 2 \mathrm{~min}$} \\
\hline & & $\begin{array}{l}\text { Lines } \\
\text { crossed }\end{array}$ & $\begin{array}{l}\text { Outer circle } \\
\text { crossed }\end{array}$ & Faecal boli \\
\hline $\begin{array}{l}\text { Toxin-injected } \\
\text { Controls } \\
\text { (neutralised toxin) }\end{array}$ & $\begin{array}{l}11 \\
12\end{array}$ & $\begin{array}{l}26.8 \pm 13 \cdot 3 \\
21 \cdot 9 \div 10 \cdot 9 \\
\text { NS }\end{array}$ & $\begin{array}{l}2 \cdot 45 \pm 3 \cdot 21 \\
1 \cdot 17 \pm 1 \cdot 40 \\
\text { NS }\end{array}$ & $\begin{array}{l}2 \cdot 36 \pm 2 \cdot 46 \\
2 \cdot 64 \pm 2 \cdot 29 \\
\text { NS }\end{array}$ \\
\hline
\end{tabular}

The values are given standard deviation.

\section{AGGRESSION: HOME-INTRUDER TEST}

Tetanus toxin was injected bilaterally into the hippocampi of twelve rats and neutralised toxin was similarly injected into twelve control animals. The rats were housed separately from the day of the operation. The test was carried out once for each rat during the third week after the operation. This is a time at which all the toxin-injected rats were hyper-reactive to handling (see table 1) and were occasionally aggressive towards the experimenter. It was therefore perhaps surprising that we found that in the home-intruder test many of the toxininjected rats were less aggressive than their controls and much more passive. Figure 1 gives an overall view of the aggressive and passive behaviours seen in the two groups of rats. It shows the mean score for each type of behaviour seen in the two groups and it is apparent that while aggressive behaviour occurs about half as often in the toxin-injected as in the control group, passive behaviour occurs much more commonly in the toxin-injected group.

In fig $2 \mathrm{a}, \mathrm{b}, \mathrm{c}$, the three behaviours which are obviously different between the two groups, that is aggression, passivity and exploration, have been compared on the basis of the individual rats' scores. It can be seen in fig $2 \mathrm{a}$ that there were more rats with low (0 or 1$)$ aggression scores in the toxininjected group and more with high scores $(p>7)$ in the control group. When the scores of the two groups are compared (Mann-Whitney U-test) the difference was almost significant at the $5 \%$ level. Figure $2 \mathrm{~b}$ demonstrates the finding that almost all the control rats exhibited no passive behaviour whereas more than half of the toxin-injected animals did show some. The difference between the two groups on this score is highly significant $(p<0.001)$. Figure $2 c$ shows that the toxin-injected rats explored much less than their controls $(p<0.001)$.

Weight loss Animals which had had tetanus toxin injected bilaterally into the hippocampus lost weight for about two weeks after the operation and then regained their pre-operative weight by about four weeks after the operation. After that they continued

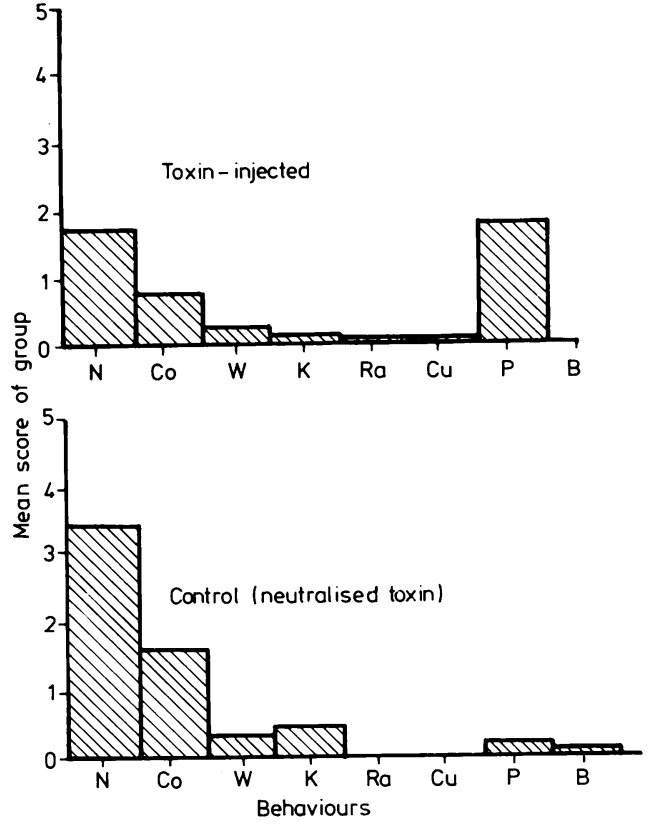

Fig 1 A comparison of the occurrence of aggressive and passive behaviours in the groups of toxin-injected and control rats. The rats were observed at $5 \mathrm{~s}$ intervals throughout a $10 \mathrm{~min}$ period after the introduction of a strange rat into the experimental (control or toxininjected) rat's cage. The scores are the average number of times the rats in the group were observed in each behaviour.
Aggressive behaviour
Passive behaviour
$N=$ nip
Co $=$ climb on
$W=$ wrestle, box
$K=$ kick, leap on, push

$$
\begin{aligned}
& R a=\text { run away } \\
& C u=\text { climb under } \\
& P=\text { passive (freeze) }
\end{aligned}
$$$$
B=\text { lying on back }
$$

to gain weight steadily, and at a rate which exceeded that of their operated controls (fig 3 ). This eventually resulted in the weights of the toxin-injected rats being significantly greater with respect to their preoperative weights than the weights of the control group.

PENTYLENETETRAZOL CONVULSION-TIME

We investigated whether the tetanus toxin-induced syndrome might potentiate pentylenetetrazol convulsions-a kindling effect. We measured the time to the first muscle-twitch and to a full convulsion after $75 \mathrm{mg} / \mathrm{kg}$ pentylenetetrazol was given intraperitoneally. Table 5 illustrates the results obtained when the pentylenetetrazol was given to the rats which had received injections 18 days previously, each of $5 \mathrm{LD}_{50}$ of tetanus toxin, bilaterally (total of $10 \mathrm{LD}_{50}$ ) into their hippocampi (their controls received injections of neutralised toxin). (At this 

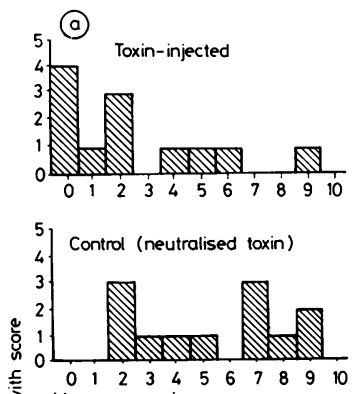
Mean aggression score

$$
\text { 민 }
$$
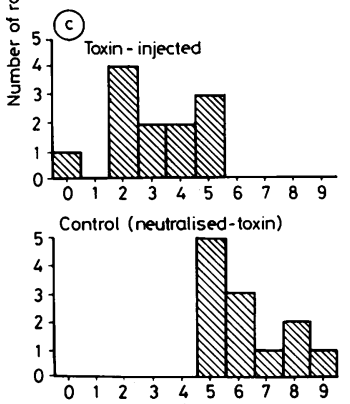

Mean exploration score

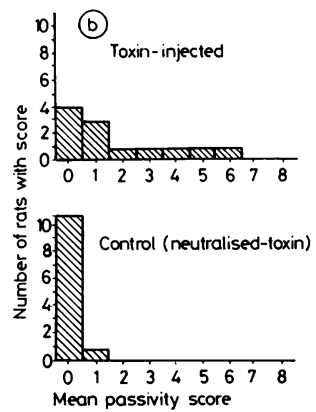

Mean passivity score

Fig 2 Distribution of aggression, passivity and exploration scores of rats in the home intruder test. The histograms represent the numbers of rats in the different groups exhibiting each score (no of each behaviour in the 10 minute test period). See legend to fig 1 for types of behaviour classified as aggressive or passive.

time after operation the toxin-injected rats were hyper-reactive and having myoclonic seizures at intervals.) There was no difference in the mean of the times that the toxin-injected and the control rats took to produce some kind of convulsion. However, there was a striking difference in the characteristics of this first convulsion. The control animals first fell on to their sides and convulsed violently, with all four limbs and the trunk musculature involved, usually with the hind and fore limbs moving in opposite

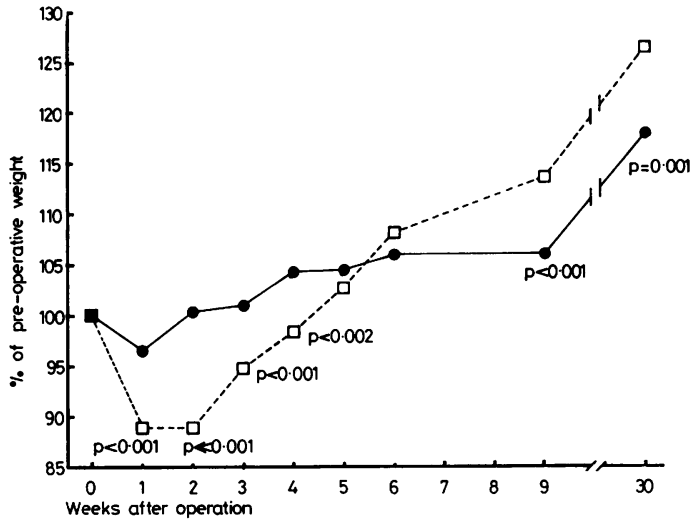

Fig 3 A comparison of the post-operative weights of toxin-injected and control rats. The rats were weighed weekly after the operation and the $\%$ of pre-operative weight calculated ( $n=12$ in each group).

Control rats (neutralised toxin)
$\square--\square$ Toxin-injected rats

directions (we have called this type of convulsion a "PTZ" convulsion in the tables). In contrast, six out of seven of the toxin-injected animals produced a seizure which was indistinguishable from the type of fit they had previously been having (as a result of the toxin injections). Thus, for a period of about 20 seconds they stood up on their hind legs and produced myoclonic jerks of the forepaws, sometimes synchronously, sometimes alternately, occasionally retracted the head in jerks, and in some cases fell back on to four paws at intervals. This type of movement then usually became intermittent and only after another minute or so would the animals produce a typical pentylenetetrazol-type fit. Thus there was a markedly prolonged time in the tetanus toxin injected rats before the production of a full tonic seizure. This time was much more variable however than the times to the first fit in these rats (or to a full seizure in the control rats).

In contrast, it was found that animals which had been given injections of toxin 5 months previously

Table 5 The timing of the effects of intraperitoneal pentylenetetrazol ( $75 \mathrm{mg} / \mathrm{kg}$ body weight) on rats given tetanus toxin, and on control rats given neutralised tetanus toxin, bilaterally into the ventral hippocampus 18 days previously (SD in parentheses)

\begin{tabular}{lllll}
\hline Treatment & $N$ & Time to first twitch & $\begin{array}{l}\text { Time to first fit of any } \\
\text { kind (see Results) }\end{array}$ & $\begin{array}{c}\text { Time to first generalised "PTZ" } \\
\text { convulsion (see Results) }\end{array}$ \\
\hline $\begin{array}{l}\text { Tetanus toxin } \\
\text { injected bilaterally } \\
\text { into the hippocampus }\end{array}$ & 7 & $45 \cdot 6( \pm 17 \cdot 4) \mathrm{s}$ & $53 \cdot 7( \pm 13 \cdot 5) \mathrm{s}$ & $125 \cdot 3( \pm 82 \cdot 9) \mathrm{s}$ \\
$\begin{array}{l}\text { Neutralised tetanus } \\
\text { toxin injected } \\
\text { bilaterally into the } \\
\text { hippocampus }\end{array}$ & 7 & $45 \cdot 4( \pm 5 \cdot 44) \mathrm{s}$ & $53 \cdot 4( \pm 6 \cdot 32) \mathrm{s}$ & $53 \cdot 4( \pm 6 \cdot 32) \mathrm{s}$ \\
\hline
\end{tabular}


(and which two weeks previously had still shown an impairment in learning ability ${ }^{12}$ ) did not differ in the time which pentylenetetrazol took to cause initial muscle twitching or a full convulsion. In this experiment, pentylenetetrazol took a similar time to cause initial muscle twitching or a full convulsion in control and experimental animals. In this experiment both control and experimental animals had similar, pentylenetetrazol-type fits.

THE EFFECT OF THE TOXIN ON THE ELECTRICAL ACTIVITY RECORDED FROM THE HIPPOCAMPUS

So far, records have been obtained from eight rats which have received unilateral hippocampal injections of tetanus toxin and which have at the same time had electrodes implanted into their hippocampi. In six of these rats there were bilateral hippocampal electrodes and in the other two rats just a unilateral electrode at the site of the injection. In these preliminary studies we have been particularly interested in two things: firstly, the time course of the development of the hippocampal focus, and secondly the relationship between the activity recorded from the hippocampus and the overt signs of complex partial seizures.

(i) The life-history of the epileptic focus

In general, the rats started having overt seizures within two days of the operation. While there was then an overall trend for the seizure frequency to increase over the next week or so, there were also enormous variations in the frequency from day to day. In most rats there seemed to be an approximately four-day cycle in seizure frequency. Figure 4 $a, b$ shows the frequency of hippocampal discharges, with and without accompanying overt signs of a fit, in two of the rats from which we have recorded. Within about the first week after the operation, discharges recorded from the hippocampi were associated with overt seizures, the animals rearing and falling and showing myoclonic jerks of the forepaws (and sometimes hindpaws). However, after about a week it was observed that some of the hippocampal discharges occurred without any overt signs of seizure, or at the most a few very small twitches of the facial musculature. These discharges frequently occurred while the animal was asleep, in which case the sleep appeared undisturbed. By about three weeks after the operation, no further overt seizures were seen, but the frequency of the hippocampal discharges remained high for a further two weeks or so. In most animals by the fifth week after the operation, the frequency of the hippocampal discharges was decreasing and no further discharges were seen after the sixth week. It is however
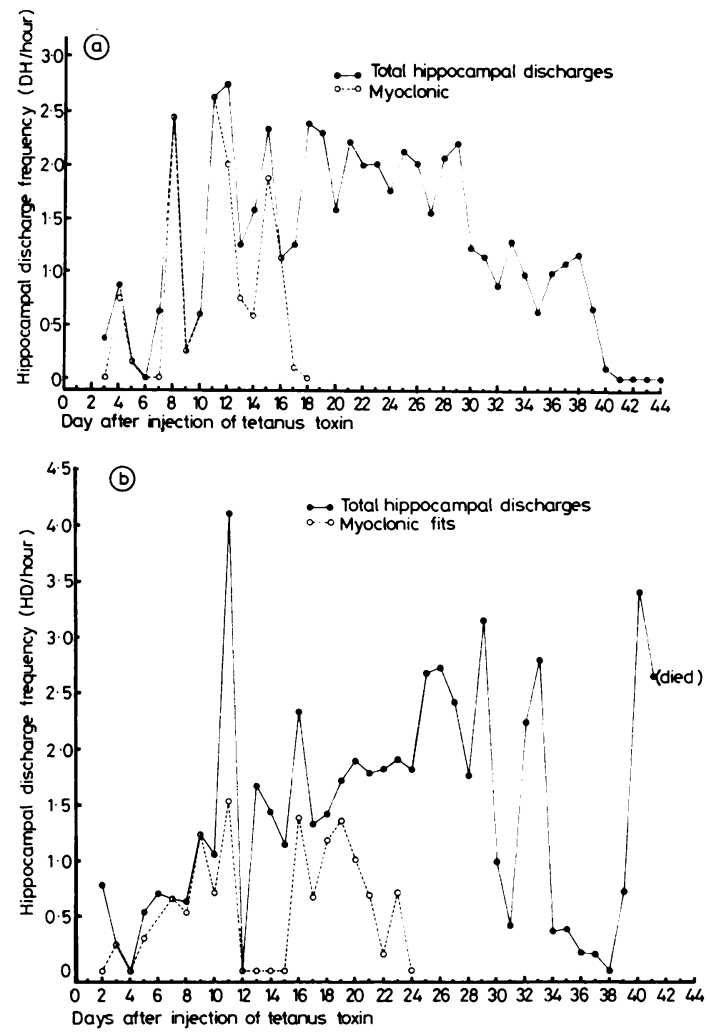

Fig 4 Frequency of hippocampal discharges, with and without overt seizures, in two rats after injections of tetanus toxin into the ventral hippocampus. $4(a)$ and 4 (b) refer to two different rats (2 and 3). In both cases 6-12 (mouse) $L D_{50}$ was injected unilaterally into the (left) ventral hippocampus and at the same operation recording electrodes were implanted in both hippocampi. The total number of hippocampal discharges was counted from the electrical record, and included all those rapid successions of "spikes" lasting more than $15 \mathrm{~s}$ (almost all of which lasted more than $30 \mathrm{~s}$ ). An overt "myoclonic" fit was recorded when the animal stood up on its hind legs and showed myoclonic jerks of the forepaws (and sometimes also of the hindpaws).

interesting to note that in one rat, whose history is illustrated in fig 4b, 39 days after operation, when the seizure frequency had fallen steeply over the preceding days, there was a sudden increase in discharge frequency and the animal died on the 41 st day after operation.

\section{(ii) Characteristics of the electrical records}

Two hippocampal discharges, from different rats, are illustrated in fig 5. Figure 5(i) shows also, for comparison, the record from the control, uninjected 
(i)

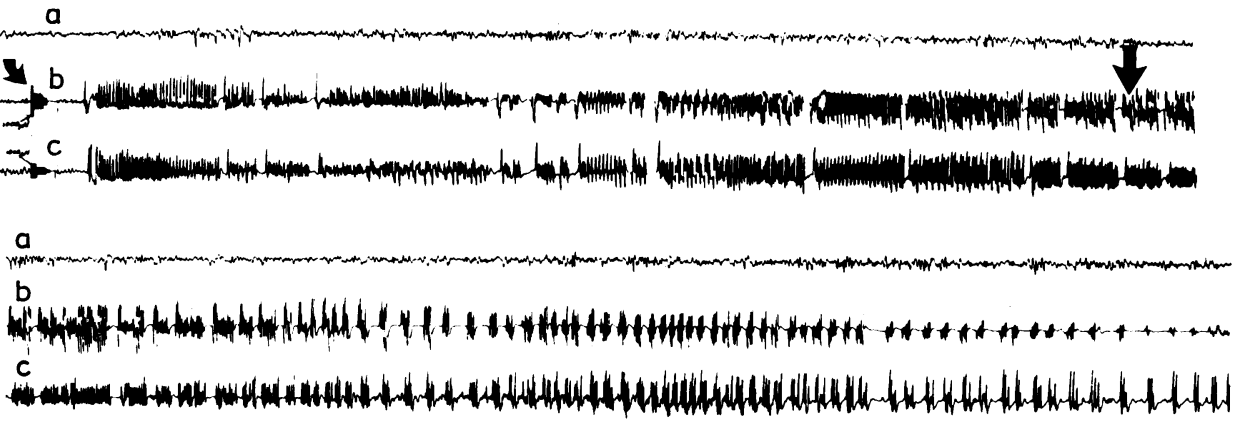

a

b

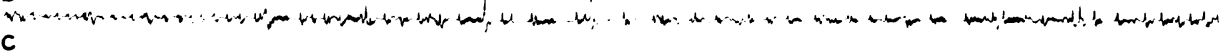

c

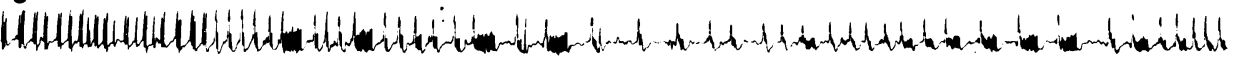

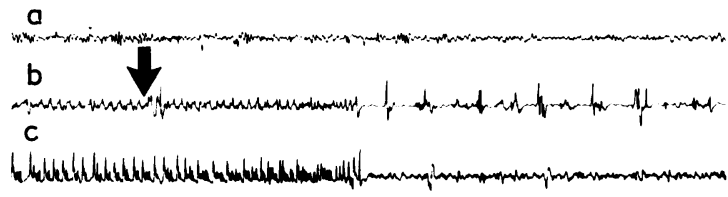

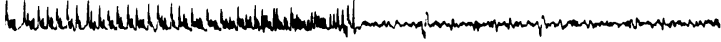

(ii)
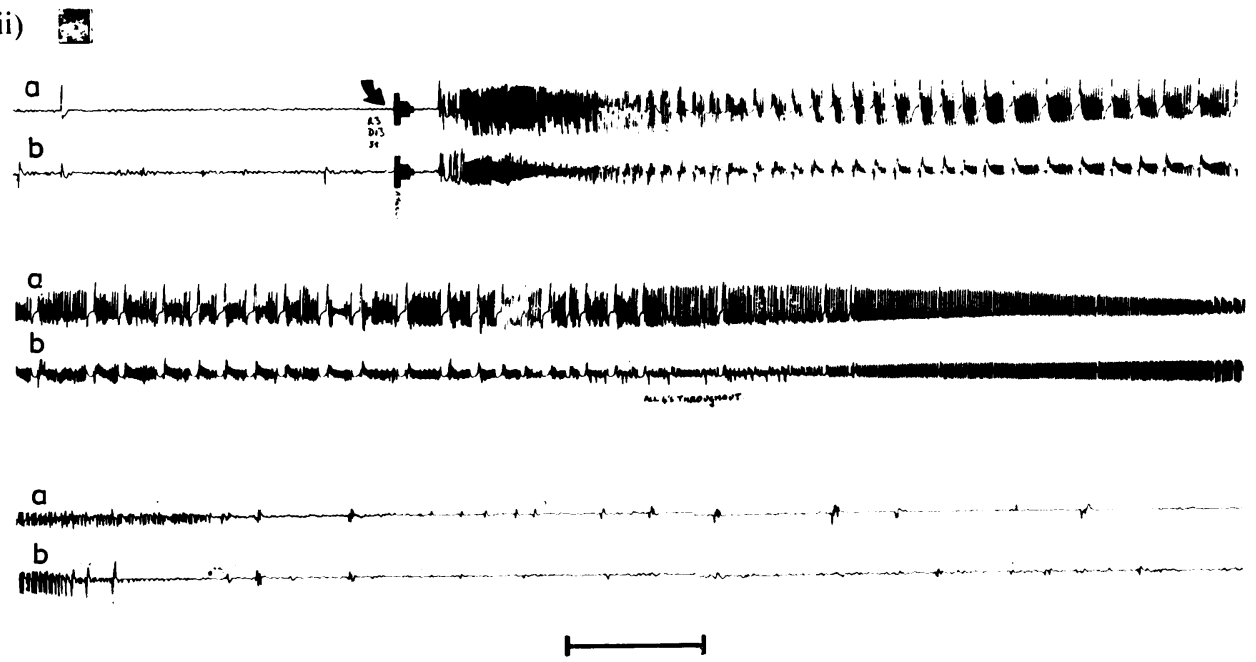

Fig 5 Electrical activity in the hippocampi during discharges.

(i): (a) Control, uninjected rat, with implanted hippocampal electrodes.

(b) Rat 2, injected hippocampus.

13 days after injection of toxin. Myloclonic jerks

(c) Rat 2, uninjected hippocampus.

(ii): (a) Rat 3, injected hippocampus.

(b) Rat 3, uninjected hippocampus. were occurring between the two points marked with $\{$ large vertical arrows.

$\{13$ days after injection of toxin. On this occasion, the discharge started while the animal was asleep $\int$ and it remained still throughout.

Calibrations. $1000 \mu \mathrm{V}$ is shown at the start of each channel, indicated by a curved arrow. The horizontal bar indicates $5 \mathrm{~s}$. 
rat. It can be seen that in both the discharges illustrated (one of which (i) was accompanied by an overt seizure while the other was not) the spiking appears to start synchronously in the two hippocampi. The records then continue to be similar on the two sides for some tens of seconds, but eventually in the record shown in fig 5(i) the spikes become much larger on the side of the hippocampus which had not been injected with tetanus toxin. This feature, of the non toxin-injected hippocampus apparently taking over during a discharge, was seen frequently in the records from all the rats. Sometimes, in addition, the non toxin-injected side would produce an independent burst of spikes after a discharge.

It was of interest to attempt to determine whether there were features of the electrical record which differed between hippocampal discharges which were accompanied by an overt fit and those which were not. To investigate this, we examined in detail the records of discharges occurring on the same day in the same rat which did and did not produce an overt tit. We were unable to find differences in the amplitude of the spikes or their frequency or in the overall appearance of the discharge. An example of the similarity of the electrical record obtained from an animal during myoclonus and on another occasion, at the same time after the start of the syndrome but where there were no overt motor signs is shown in fig 6 .

Another consistent feature of the electrical records was the occurrence of large interictal spikes $(800 \mu \mathrm{v}$ or larger). These were observed during the weeks when hippocampal discharges were occurring and disappeared again when the discharges ceased. Figure 7 shows a characteristic piece of interictal record illustrating these large spikes, compared with the record obtained from the control, uninjected rat.

\section{Discussion}

The behavioural results show that the injection of tetanus toxin into the hippocampus in rats makes the animals over-reactive to handling and to the stimulation involved during testing in the open field without producing an increase in their general activity in their home cages. The finding that there was no difference between the number of faecal boli produced by the experimental animals and the controls in the open field suggests that there was no effect of the toxin injection on emotionality (for a discussion see ref 15). In some of the animals the hyper-reactivity is associated with sporadicaggressive behaviour - the animals on some occasions viciously biting objects such as the experimenter's hand or a pencil when they were introduced into the cage. We attempted to investigate this aggressive behaviour

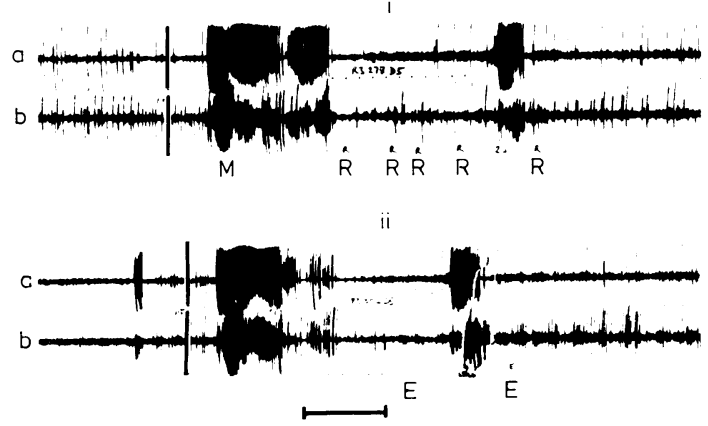

Fig 6 Comparison of the electrical records from the hippocampi obtained when (i) the discharge was accompanied by a myoclonic seizure, (ii) there were no myoclonic signs. The records were obtained from Rat 3 during the night, on the fifth day after the injection of the toxin $((i)$ at $20.00 \mathrm{hrs}$ and (ii) at $24.00 \mathrm{hrs}$ ). (For further details see legend to fig 4 and Methods). Record labelled " $a$ " is in each case from the left, injected, hippocampus and " $b$ " from the opposite uninjected side. At $R$ the animal reared. At $M$ myoclonic jerks started. At $E$ the animal started to explore. Calibrations: The $1000 \mu \mathrm{V}$ is drawn at the left hand end of the discharge on each channel. The horizontal bar indicates $50 \mathrm{~s}$.

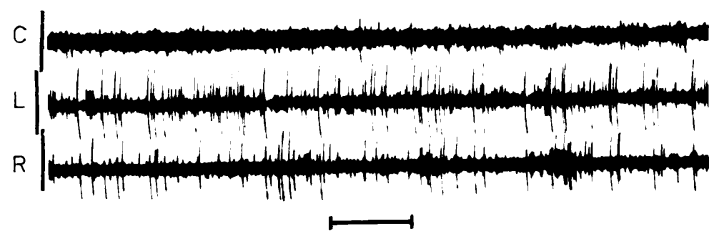

Fig 7 Interictal spikes occurring bilaterally in the hippocampi.

C-record from the hippocampus of a control rat.

$L]$ Rat 2, injected hippocampus 5 days after

\}$\quad$ injection of

$R$ Rat 2, uninjected hippocampus $\int$ tetanus toxin. Calibrations. The $1000 \mu \mathrm{V}$ is drawn at the left hand end of each channel. The horizontal bar indicates $50 \mathrm{~s}$.

quantitatively by measuring the response of rats (in a 10 minute period) to an "intruder" rat put into their home cage. Rather surprisingly the toxininjected rats were less aggressive and showed more passive behaviour in the home intruder test than did their controls. It would thus seem that the aggressive behaviour, which is anyway only seen sporadically, is perhaps rather specifically aroused by handling by the experimenter. Both occasional aggressive episodes $^{16}$ and generally more passive responses have been reported as occurring in some patients with temporal lobe epilepsy. However, in humans with temporal lobe epilepsy who show abnormal behaviour it is often difficult to disentangle whether 
the behaviour disorder is an integral part of the disease or a result of seizures or of drug treatment. The tetanus toxin-induced epileptiform syndrome shows that an agent which causes the production of an epileptiform focus can also simultaneously cause abnormal behaviour.

It is possible that the variable incidence of aggressive behaviour in the tetanus toxin-injected rats may be related to whether the epileptic focus in the hippocampus produces secondary stimulation of the amygdala. It was shown by McDonough and Kesner $^{17}$ that brief electrical stimulation of the hippocampus can lead to discharges in the amygdala. Electrical stimulation of the amygdala is well known to be able to produce fear or rage (or both) reactions.

The interesting finding of the difference in the characteristics of the seizures produced by pentylenetetrazol in the toxin-injected animals as compared with their controls might be relevant to the changes occurring in the brain in human epileptic patients. It appears as if the pentylenetetrazol is able to facilitate the production of the type of electrical discharge which has been produced previously in the animals as a result of the tetanus toxin injection. In contrast, the toxin-injected brain seems to be more resistant to the general convulsive action of the pentylenetetrazol. This observation could be interpreted as suggesting that during the epileptic syndrome, parts of the brain outside the hippocampus have become less sensitive to a convulsant action. Indeed, in the present experiments we have demonstrated that some such promotion of damping mechanisms of the brain must occur in the toxininjected animals since they have overt myoclonic seizures accompanying their hippocampal discharges during the first few weeks after toxin injection but then although the frequency, intensity and general appearance of discharges remains similar for several further weeks, the overt seizures are no longer seen.

The post-operative weight loss which occurs in the toxin-injected animals, and to a much lesser extent in their controls, is probably due to loss of appetite rather than to the increased motor activity associated with the fits, since the rats begin to regain weight at a time when the fits are still occurring frequently. We have three times repeated the finding that the increased rate of weight gain in the toxin-injected animals is maintained after they regain their preoperative weight. Glaser (personal communication) has observed a comparable rebound weight increase in some underweight children with temporal lobe epilepsy after they responded to treatment.

Experiments described elsewhere ${ }^{1112}$ on the memories of toxin-injected rats for a test learnt prior to the induction of the epileptiform syndrome show that at least up to nine weeks after operation the animals' memories are impaired. This is at a time about four weeks after the electrical activity in the rats' hippocampi would have returned to normal and about six weeks after they have stopped having overt seizures. Furthermore, animals which have recovered from the syndrome also are impaired in learning new tasks. ${ }^{18}$ It is of course dangerous to draw conclusions from "animal models" of human diseases but these findings are at least reminiscent of the problems in memory, learning and attention which are frequently seen in children with temporal lobe epilepsy. ${ }^{19}$ It will be interesting to investigate in the future whether it is possible to find drugs which will treat the abnormal behaviour of the toxininjected animals either as well as or independently of the seizures. It is of importance to confirm (or not) whether the hyper-reactivity and aggression are dependent on the occurrence of overt seizures, and to answer a similar question with respect to the longterm impairments in learning and memory. It may be relevant here that Weinberger and Killam ${ }^{20}$ have shown learning impairments in baboons with seizures the extent of which were not apparently correlated with frequency of overt seizures.

It is likely that tetanus toxin produces the epileptic focus by blocking the release of GABA from nerve terminals in the hippocampus. ${ }^{5}$ The behavioural effects of the toxin injection could be due directly to such a block of GABA-mediated transmission. However, the results need not point to any specific role of GABA. It could be predicted that the disorganisation of hippocampal neuronal mechanisms by an epileptic focus within the structure (which apparently produces a contralateral epileptic focus as well (see also ref 21) ) would disrupt a wide range of brain functions.

We thank Professor G Glaser for helpful discussions. We are grateful to the British Epilepsy Fund, CIBA-GEIGY Limited, and St Hilda's College, Oxford, for financial support.

\section{References}

${ }^{1}$ Bear DM, Fedio P. Quantitative analysis of interictal behaviour in temporal lobe epilepsy. Arch Neurol 1977;34:454-67.

${ }^{2}$ Glaser GH. Epilepsy: neuropsychological aspects. In: Arieti S, ed. American Handbook of Psychiatry. New York: Basic Books, 1975:314-55.

${ }^{3}$ Ounsted C, Lindsay J, Norman R. Biological factors in temporal lobe epilepsy. In: Clinics in Developmental Medicine, No. 22. London: The Spastics Society Medical Education and Information Unit in association with William Heinemann Medical 
Books Ltd, 1966.

${ }^{4}$ Mellanby J, George G, Robinson A, Thompson P. Epileptiform syndrome in rats produced by injecting tetanus toxin into the hippocampus. $J$ Neurol Neurosurg Psychiatry 1977;40:404-14.

${ }^{5}$ Collingridge GL, Thompson PA, Davies J, Mellanby J. In vitro effect of tetanus toxin on release of GABA from hippocampal slices. $J$ Neurochem, 1981 ;37:103941.

${ }^{6}$ Curtis DR, Felix D, Game CJA, McCullogh RM. Tetanus toxin and the synaptic release of GABA. Brain Res 1973;51:358-62.

${ }^{7}$ Collingridge GL, Collins GGS, Davies J, James TA, Neal MJ, Tongroach P. Effect of tetanus toxin on transmitter release from the substantia nigra and striatum in vitro. J Neurochem 1980;34:540-7.

${ }^{8}$ Collingridge GL, Davies J. Reversible effects of low doses of tetanus toxin on synaptic inhibition in the substantia nigra and turning behaviour in the rat. Brain Res 1980;185:455-9.

${ }^{9}$ Davies J, Tongroach P. Tetanus toxin and synaptic inhibition in the substantia nigra and striatum of the rat. J Physiol (Lond) 1979;290:23-36.

${ }^{10}$ Mellanby J, Green J. How does tetanus toxin act? Neuroscience 1980;6:281-300.

${ }^{11}$ Mellanby J, George G. Tetanus toxin and experimental epilepsy in rats. In: Ceccarelli B, Clementi F, eds. Advances in Cytopharmacology, Vol. 3. New York: Raven Press, 1979:401-8.

12 George G, Mellanby J. Memory deficits in an experimental hippocampal epileptiform syndrome in rats. Exp Neurol 1982, in press.
${ }^{13}$ Mellanby J, Mellanby $H$, Pope D, van Heyningen WE. Ganglioside as a prophylactic agent in experimental tetanus in mice. J Gen Microbiol 1968;54:161-8.

${ }^{14}$ File SE, Deakin JFW, Longden A, Crow TJ. An investigation of the role of the locus coeruleus in anxiety and agonistic behaviour. Brain Res 1979; 169:411-20.

${ }_{15}$ Walsh RN, Cummins RA. The open-field test; a critical review. Psychol Bull 1976;83:482-504.

${ }^{16}$ Lindsay J, Ounsted C, Richards P. Long-term outcome in children with temporal lobe seizures. III. Psychiactric aspects in childhood and adult life. Dev Med Child Neurol 1979;21:630-6.

17 McDonough JH, Kesner RP. Amnesia produced by brief electrical stimulation of amygdala or dorsal hippocampus in cats. J Comp Physiol Psychol 1971; 77:171-8.

${ }^{18}$ Mellanby J, Renshaw M, Cracknell H, Rands G, Thompson P. Long-term impairment of learning ability in rats following an experimental hipposampal epileptiform syndrome. Exp Neurol 1982, in press.

19 Stores G, Hart J, Piran N. Inattentiveness in schoolchildren with epilepsy. Epilepsia 1978;19:169-76.

${ }^{20}$ Weinberger SW, Killam EK. Alterations in learning performance in the seizure-prone baboon: effects of elicited seizures and chronic treatment with Diazepam and phenobarbital. Epilepsia 1978;19: 301-16.

${ }^{21}$ Glaser GH, Yu RK. A model of hipposampal epilepsy produced by tetanus toxin. Neurology (Minneap) 1977;27:33. 